\title{
Differences in fertility and suckling patterns between primiparous and multiparous rhesus mothers (Macaca mulatta)
}

\author{
M. Gomendio
}

$M R C$ Unit for the Development and Integration of Behaviour, University of Cambridge, Madingley, Cambridge, CB3 $8 A A, U K$

\begin{abstract}
Summary. Primiparous females gave birth around the same time as multiparous nonlactating females, and earlier than did multiparous lactating females. No differences in birth sex ratio were found between primiparous and multiparous females.

During the breeding season following birth, primiparous mothers returned to oestrus later than did multiparous mothers, and while few primiparous mothers conceived successfully during that season, most multiparous mothers did.

Primiparous females suckled their infants more frequently than did multiparous females at all ages; infants of primiparous females also made more nipple contacts per bout, and had shorter sucking bouts. When mothers came into oestrus, suckling frequency drastically increased for primiparous females, but not for multiparous females, magnifying the differences between the two groups. After the first oestrus, suckling frequency declined for all mothers, but multiparous mothers had consistently lower suckling frequencies than did primiparous mothers. The high suckling frequency, and numerous nipple contacts per bout, found among primiparous mothers are likely to be related to the low reproductive chances that these females faced during the breeding season. Multiparous mothers seemed to compensate for their low suckling frequency by lengthening the suckling bouts, and this suckling pattern did not hinder their reproduction.

It is argued that primiparous mothers might have to suckle their infants more frequently because they can only produce milk at slow rates, being in this way forced into a reproductively inhibiting suckling pattern. However, the delay in subsequent reproduction could be ultimately advantageous for primiparous mothers if it enhanced infant survival, and allowed the mothers to regain physical condition before reproducing again.
\end{abstract}

Keywords: parity; fertility; suckling; lactation; macaques

\section{Introduction}

Human and non-human primate females reach menarche before growth is completed (Mori, 1979; Watts \& Gavan, 1982; Lancaster, 1984, 1986; Anderson, 1986), entering thereafter a period of adolescent sterility that can last from 1 year, as in rhesus macaques (Wilson et al., 1984, 1986; Wilson \& Gordon, 1989), up to 2 years, as in chimpanzees and humans (Lancaster, 1986). Eventually, an increase in body weight, associated with an increase in serum GH and prolactin, precedes the first ovulation (Wilson et al., 1984). From this event until the end of their reproductive careers, females experience a series of recurring cycles, each of them consisting of 3 phases: ovulatory interval (or waiting time to conception), pregnancy and post-partum amenorrhoea (Short, 1976; Bongaarts \& Potter, 1983; Dunbar, 1988). 
Lactation is a costly activity in energetic terms (Martin, 1984; Oftedal, 1984; Prentice \& Whitehead, 1987), which can lead to a deterioration in maternal body condition and, consequently, to high mortality rates among lactating mothers (primates: Altmann, 1980, 1983; red deer: CluttonBrock et al., 1982a, b, 1989). Human females seem to be relatively protected against losses in body condition during lactation, probably due to their greater fat reserves and low cost of lactation per unit time (Hartmann et al., 1984; Oftedal, 1984; Prentice \& Whitehead, 1987; Lunn, 1988). Lactation can also depress subsequent reproduction, and this effect is so strong in human and non-human primates that lactation is considered to be the main proximate mechanism regulating 'natural' fertility (Short, 1976, 1984; Bongaarts \& Potter, 1983; Nicolson, 1987; Campbell \& Wood, 1988; Thapa et al., 1988). The presence of a suckling infant delays the resumption of oestrus and increases the number of sexual cycles before conception (Short, 1976, 1984, 1985; Altmann et al., 1978; Konner \& Worthman, 1980; Nicolson, 1982; Elias et al., 1986; Lee, 1987; Stewart, 1988; Gomendio, 1989). In seasonally breeding species, like the rhesus macaque, lactating females can only sustain a small number of ovulations during the breeding season (Pope et al., 1986), and are less likely to become pregnant in any given year than non-lactating females (Drickamer, 1974; Gordon, 1981; Hiraiwa, 1981; Paul \& Thommen, 1984; Scucchi, 1984; Wolfe, 1986; Lee, 1987; Gomendio, 1989). Furthermore, the extent to which lactation delays subsequent reproduction depends on the suckling pattern; in particular, the frequency of suckling bouts seems to have a considerable influence upon fertility (man: Konner \& Worthman, 1980; Howie \& McNeilly, 1982; Short, 1984; Wood et al., 1985; vervets: Lee, 1987; gorillas: Stewart, 1988; Stewart et al., 1988; macaques: Gomendio, 1989).

Physiological work suggests that the suckling stimulus on the nipple acts by increasing levels of opiates which, in turn, depress the secretion of gonadotrophin-releasing hormone (GnRH) within the hypothalamus. The decrease in GnRH secretion prompts the suppression of luteinizing hormone (LH) output, which ultimately prevents the occurrence of normal ovulatory cycles (Short, 1984; Pope et al., 1986; Gordon et al., 1987; McNeilly, 1988; McNeilly et al., 1988).

Primiparous females suffer high infant mortality rates and go through a marked depression in fertility after their first birth (Drickamer, 1974; Dolhinow et al., 1979; Mori, 1979; Hiraiwa, 1981; Silk et al., 1981; Burton \& Sawchuk, 1982; Strum \& Western, 1982; Wilson et al., 1983, 1988; Pope et al., 1986; Altmann et al., 1988; Silk, 1988; also reviews by Anderson, 1986; Lancaster, 1986; Nicolson, 1987). In seasonal species, primiparous females which are lactating show the shortest ovulatory period (being the last ones to start ovulating and among the first to stop), and the highest proportion of abnormal ovulations among all reproductive females, resulting in very few of them becoming pregnant (Pope et al., 1986; Wilson et al., 1988). Attempts have been made to relate these reproductive deficiencies to physical condition or lactational patterns, but no compelling evidence has so far been found. The aim of this paper is to examine the reproductive events during the year following birth in primiparous and multiparous females, and to try to uncover any existing links between differences in fertility and differences in suckling patterns.

\section{Materials and Methods}

\section{The Madingley colony}

The present colony of rhesus macaques (Macaca mulatta) kept at Madingley was established in 1982, and since then all the groups have been stable in composition. The colony has 6 social groups, each of them consisting of a single adult male with several females and their offspring. To maintain a situation as similar as possible to the social structure and social dynamics found among wild populations (reviewed in Melnick \& Pearl, 1987; Dunbar, 1988), females are kept in their natal groups, which has led to the formation of matrilines, while young males are removed at 3-4 years of age. The adult male in each group is regularly replaced to prevent inbreeding.

Each social group inhabits an independent enclosure, and all the monkeys have ample visual, olfactory and auditory communication with members of the other social groups. Each enclosure has an outdoor pen (approximately $8 \times 3 \times 4 \mathrm{~m}$ ) and a heated indoor room (approximately $2.5 \times 1.5 \times 2 \mathrm{~m}$ ). The monkeys move freely from one to the other through a small flap-door. The enclosures are provided with shelves, wooden bars, swings and large pipes which 
add new spatial dimensions. Every day the enclosures are cleaned early in the morning, and the animals are fed immediately afterwards with pelleted monkey food, nuts and sunflower seeds. They are fed for a second time between 13:00 and 14:00 $\mathrm{h}$ with fresh fruit and vegetables.

\section{Reproductive data}

Macaques are seasonal breeders (Vandenbergh \& Vesey, 1968; Drickamer, 1974; Gordon, 1981; Walker et al., 1983; Pope et al., 1986). At Madingley, the breeding season takes place during autumn and winter, and females give birth during spring and summer. The breeding season lasts for about 3 months, a phenomenon common to most macaque populations (Melnick \& Pearl, 1987).

Although changes in the colour of the perineal skin have been reported to occur around ovulation in rhesus monkeys (Czaja et al., 1975), at Madingley there was great inter-individual variation in this respect. In most cases, no clear external morphological changes could be detected, and so female reproductive condition had to be inferred from the behaviour of the females. The term 'oestrus' is therefore used to refer to the appearance of proceptive and receptive behaviour, leading to copulatory behaviour with the male (see Hrdy \& Whitten, 1987). No attempt was made to determine whether ovulation accompanied a given oestrous period. All mature females came into oestrus every breeding season, but not all of them conceived every year. The first day on which a female was seen in oestrus was considered as the start of the breeding season for the whole colony. For each female, the first day on which she was observed interacting sexually with the male was taken as the beginning of her first oestrous period. Generally, females underwent several consecutive oestrous periods before they became pregnant, and females sometimes interacted sexually with the male after they had already conceived. Conception dates were calculated by counting back 168 days from the next birth (van Wagenen, 1972; Wilson et al., 1988).

In any given year, the date of the first birth was considered as the start of the birth season for the whole colony. Inter-birth intervals were divided into two categories depending on whether females reproduced in consecutive years ( 1 year inter-birth interval) or in alternate years ( 2 year inter-birth interval). This criterion was chosen because it reflects the drastic differences in reproductive rates that females in seasonally breeding species experience, as opposed to the more gradual differences that are characteristic of non-seasonally breeding primates. It should be noted that this method contrasts with other reports on seasonally breeding primates which focus on differences within 1 year inter-birth intervals (e.g. Silk, 1988).

Data on the timing of oestrous cycles for all the colony females were collected during the breeding seasons of $1985 / 1986$ and $1986 / 1987$. For this purpose, systematic observations were carried out daily for all groups to determine which females were in oestrus throughout the entire breeding season. The precise timing of first oestrus was determined in 30 cases.

Birth dates from 1985, 1986 and 1987 have been used to determine conception dates for a total of 38 cases.

Analyses of inter-birth intervals and birth sex ratio include data collected from 1983 to 1987 . Before this study began (1985), data were collected by a number of researchers working under the supervision of Dr M. J. A. Simpson. The lengths of 39 inter-birth intervals were calculated, and the sex of 51 offspring determined. Data from the year following the establishment of the colony (1982) have not been included to avoid any possible confounding factors derived from the early stages of group formation.

\section{Suckling data}

Data on suckling patterns were recorded from August 1986 until August 1987, for 12 macaque infants (6 males and 6 females) born in 1986 (Table 1). There were 8 multiparous and 4 primiparous mothers. In this study, a 'primiparous' mother was defined as a mother who was raising her first surviving infant (i.e. ignoring previous abortions or birth to dead infants).

Data on suckling behaviour were collected from the age of 4 months. From then on, each month of age was divided into two 15-day long periods for each infant. At least two independent suckling samples were collected during each 15-day period. Observations were made from 10:00 to 13:00 $\mathrm{h}$ and from 14:00 $\mathrm{h}$ to sunset.

Suckling sequences were registered in detail in 1-h long observation sessions. However, observations were stopped after $30 \mathrm{~min}$ if all the members of a group had fallen asleep during that period. When this happened, at least two other complete observation sessions per 15 days were recorded for that infant. The precise timings of all initiations and endings of nipple contacts were recorded by using a stopwatch.

\section{Analyses}

Suckling sequences consisted of temporal clusters of nipple contacts. However, these clusters were not clear enough to be objectively recognized, and so log survivorship analysis was used to define a bout statistically (see Martin \& Bateson, 1986). This method determines the minimum interval separating consecutive bouts, (i.e. the bout criterion interval. Any interruptions lasting for longer than the bout criterion interval are then treated as inter-bout intervals, while any interruptions that are shorter than the bout criterion interval are treated as within-bout breaks. To estimate the bout criterion interval, the cumulative frequency of gap lengths (on a logarithmic scale) is plotted against gap length (on a linear scale). This method is based on the assumption that within- and between-bout intervals 
Table 1. Sample of infants for which suckling data were collected

\begin{tabular}{lrllc}
\hline Infant & Date of birth & Sex & Parity & Pregnant \\
\hline Manuel & 8 May 1986 & Male & Multiparous & Yes \\
Oona & 16 May 1986 & Female & Multiparous & No \\
Gabriel & 19 May 1986 & Male & Multiparous & Yes \\
Jomo & 20 May 1986 & Male & Multiparous & Yes \\
Zorba & 21 May 1986 & Male & Multiparous & Yes \\
Balbina & 21 May 1986 & Female & Primiparous & No \\
Lola & 29 May 1986 & Female & Primiparous & No \\
Halszka & 18 June 1986 & Female & Multiparous & Yes \\
Gretel & 19 June 1986 & Female & Multiparous & Yes \\
Urban & 24 June 1986 & Male & Primiparous & Yes \\
Victor & 25 June 1986 & Male & Primiparous & No \\
Petra & 27 July 1986 & Female & Multiparous & No \\
\hline
\end{tabular}

Pregnant refers to whether the mother reproduced again during the following year.

are generated by two random processes with different rate constants, giving short within-bout intervals and long interbout intervals. If there are many short within-bout intervals and a few long inter-bout intervals, in the graphical representation a rapidly declining slope should appear distinctly separated from a slowly declining portion by a 'break point'. The interval corresponding to this break point can be considered to be the bout criterion interval. This interval was found to be $60 \mathrm{sec}$, which coincides with that found in other primate species (Lee, 1987; Stewart, 1988). Thus, when an infant interrupted nipple contact for $>60 \mathrm{sec}$ the suckling bout was considered to be finished, while if the interruption was $<60 \mathrm{sec}$ long it was treated as a within-bout break (for further details see Gomendio, 1988). It therefore follows that the basis for such a definition of bout is statistical, rather than physiological. Since it is still unclear at what level(s) the suckling stimulus operates (i.e. has physiological consequences), both the level of suckling bouts and the finer level of within-bout contacts were considered in this study (see below).

Nutritive suckling could not be distinguished from non-nutritive suckling.

The suckling variables analysed in this study were frequency of suckling bouts (per hour), duration of the suckling bouts ( $\mathrm{min}$ ), and number of nipple contacts (per bout). This last variable refers to the number of times contact was established and then interrupted for $<60 \mathrm{sec}$ during a given suckling bout. For example, there was 1 nipple contact per bout when there were no interruptions during that bout, 2 nipple contacts per bout when there had been one interruption, and so on.

Most results are presented in relation to months of age or, alternatively, 15-day blocks. When analyses were done in relation to the timing of specific reproductive events, such as first oestrus or conception, the 15-day period in which such an event took place has been considered. When the results include a broader time scale before and after these events, this was done by including data from the 15-day age periods which preceded and followed these events. In this case, the age period in which first oestrus or conception occurred is referred to as point ' 0 ', the preceding and following age periods as -0.5 and +0.5 months, and so on.

\section{Statistics}

The main statistical analyses include: $\chi^{2}$, Mann-Whitney, and analysis of variance. All probabilities were twotailed. Combined means were derived from the means of each separate infant. Standard errors of the mean (s.e.m.) (see Martin \& Bateson, 1986) accompany mean values when relevant.

For the analyses of variance, all variables were tested for normality. Those that were not normally distributed were transformed as recommended in Martin \& Bateson (1986) (see also Sokal \& Rohlf, 1981). Frequencies were corrected by using square-root transformation, and proportions and percentages were corrected by using arcsine-square root transformation. Transformed data were then re-tested for normality, satisfying the tests in all cases.

\section{Results}

\section{Timing of births, sex ratio and inter-birth intervals}

Since the establishment of the new rhesus colony at Madingley (from 1983 to 1987), 6 out of 10 females have had their first surviving infant when they were 4 years old, and the remaining females have started reproducing at 3 ( 2 females) or 5 ( 2 females) years of age.

During the birth season, multiparous females who had not reared an infant during the previous year (i.e. non-lactating multiparous) were the first to give birth $(20 \cdot 33 \pm 7 \cdot 08$ days after the start of 
the birth season, $N=9$ ), followed shortly afterwards by the primiparous females $(26 \cdot 73 \pm 6 \cdot 52$ days, $N=11$ ). No significant differences between these two groups were found. However, multiparous females who had reared an infant during the previous year (i.e. lactating multiparous) gave birth 1 month later on average $(58.33 \pm 6.39$ days, $N=18)$, the differences between this group and the other two being significant (lactating multiparous versus non-lactating multiparous: Mann-Whitney, $\mathrm{U}=17 \cdot 5, P=0.0007$; lactating multiparous versus primiparous: Mann-Whitney, $\mathrm{U}=35 \cdot 5, P=0 \cdot 002$ ).

Primiparous mothers gave birth to a somewhat smaller proportion of males ( 4 cases out of 10$)$ than females ( 6 cases), a trend that was also found among multiparous females $(\mathrm{N}=41$, males, $46.34 \%$; females, $53.66 \%$ ). There was no significant difference between the two groups of mothers $\left(\mathrm{df}=1, \chi^{2}=0 \cdot 131\right)$.

However, these two groups of mothers did differ significantly with respect to the length of the interval between two consecutive births (inter-birth interval). While only 1 primiparous female out of 7 had another infant in the year following the birth of their first surviving infant, most multiparous mothers gave birth again during the following breeding season $(77.42 \% 1$ year interval, $\mathrm{N}=31)\left(\mathrm{df}=1, \chi^{2}=10 \cdot 113, P=0 \cdot 001\right)$.

\section{Developmental trends of suckling patterns}

The suckling patterns of primiparous and multiparous mothers were compared to see whether there were any differences in suckling behaviour, and, if so, whether they might be related to the differences found in short-term fertility.

Infants of primiparous females sucked significantly more frequently than did infants of multiparous mothers over all the age range considered (Fig. 1a). This difference was already present by 4 months of age when infants of primipares were being suckled at around 6 bouts per hour, whilst infants of multipares were sucking with a frequency of only 3.5 bouts/h (Mann-Whitney, $\mathrm{N}_{1}=7$, $\mathrm{N}_{2}=4, \mathrm{U}=5, P=0.05$ ). After a somewhat parallel decline in frequencies with age for both groups, between 7 and 8 months of age infants of primiparous females started sucking more frequently, giving rise to a marked peak which magnified the difference between the two groups during this period (Mann-Whitney, $\mathrm{N}_{1}=8, \mathrm{~N}_{2}=4$; Month 6, $\mathrm{U}=3, P=0.01$; Month 7.5, $\mathrm{U}=1$, $P=0.004$ ). It was precisely during these ages when most mothers came into oestrus (see below). After this peak, sucking frequencies started decreasing again for infants of primiparous mothers, while infants of multiparous mothers continued the consistent decline with age that they had shown from the beginning of the period considered.

The number of nipple contacts made per bout also declined with age in both groups (Fig. 1b). Infants of primiparous mothers tended to make more independent nipple contacts within a bout than did infants of multiparous mothers, except at 10 and 11 months of age, when this tendency was reversed.

Finally, all young infants sucked in bouts of between 3 and 4 min in duration and, thereafter, the bouts became longer, reaching a peak at 7 (multiparous) or 8 (primiparous) months of age, after which they gradually became shorter again (Fig. 1c). Although the duration of suckling bouts was similar for both groups at 4 months, infants of multiparous mothers increased bout length more rapidly from then on, and after reaching a peak of $8 \mathrm{~min}$ remained fairly constant, while infants of primiparous females markedly decreased the duration of their bouts after their own peak of $7 \mathrm{~min}$. These differences resulted in significantly longer sucking bouts for infants of multiparous females over all the age range considered.

\section{Suckling patterns during the breeding season}

During the following breeding season, infants of primiparous mothers were on average 1 month older when their mothers first came into oestrus than were infants of multiparous mothers (primiparous, $8.62 \pm 0.55$ months, $\mathrm{N}=4$; multiparous, $7.62 \pm 0.40$ months, $\mathrm{N}=8$; Mann-Whitney, 


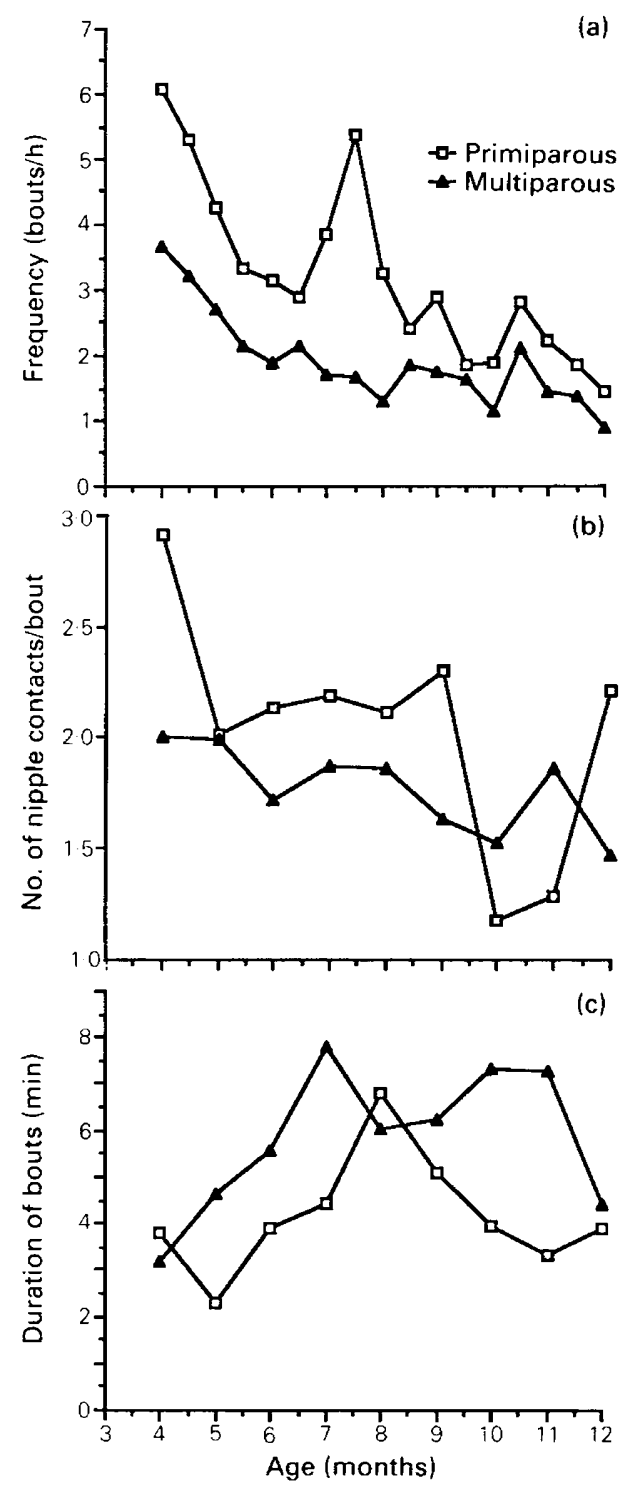

Fig. 1. Differences in suckling patterns between primiparous and multiparous mothers throughout the age range considered: (a) frequency of suckling bouts (2-factor ANOVA: infant's age, $\mathrm{df}=16, \mathrm{~F}=3.762, P=0.0001$; parity, $\mathrm{df}=1, \mathrm{~F}=27.464, P=0.0001$ ); (b) number of nipple contacts per bout (2-factor ANOVA: infant's age, df $=8, \mathrm{~F}=2 \cdot 714, P=$ 0.01 ; parity, $\mathrm{df}=1, \mathrm{~F}=3.446, P=0.06$ ); and (c) duration of suckling bouts (2-factor ANOVA: infant's age, $\mathrm{df}=8, \mathrm{~F}=1 \cdot 094$, N.S.; parity, $\mathrm{df}=1, \mathrm{~F}=5 \cdot 119, P=0.02$ ).

$\mathrm{U}=8.5$, N.S.). Because of these differences in age at a time when crucial reproductive events were taking place, analyses in relation to these events, rather than age, were carried out to see whether the differences in suckling patterns found became magnified at this time.

Primiparous mothers started cycling about 2.5 months after the start of the breeding season $(76 \pm 7 \cdot 15$ days, $N=4$ ), while multiparous mothers came into oestrus around 1.5 months after the beginning of the season ( $42.75 \pm 6.6$ days, $\mathrm{N}=8$ ) (Mann-Whitney, $\mathrm{U}=2, P=0.008$ ). Furthermore, those mothers who subsequently became pregnant, irrespective of parity, conceived during 
the first 2 months after the start of the breeding season $(65 \cdot 14 \pm 9 \cdot .57$ days, $N=7)$, before the average primiparous female had started cycling.

During those age periods in which the mother was seen in oestrus, primiparous mothers suckled their infants nearly twice as often as did multiparous mothers, the difference between the two groups being statistically significant (Fig. 2a). However, no differences in the number of nipple contacts made per bout while the mother was in oestrus were found (Fig. 2b). Finally, although infants of primiparous mothers tended to have shorter suckling bouts, no significant differences in suckling bout length during oestrus were found (Fig. 2c).
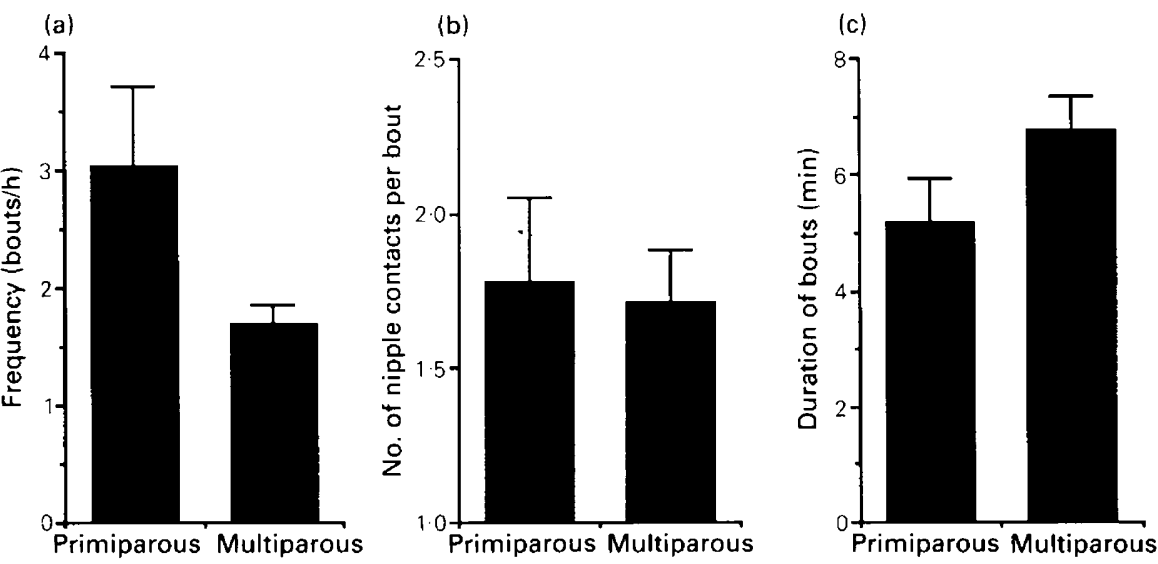

Fig. 2. Differences in suckling behaviour during oestrus between primiparous $(N=4)$ and multiparous $(\mathrm{N}=8$ ) females: (a) frequency of suckling bouts (Mann-Whitney, $\mathrm{U}=5, P=$ 0.04); (b) number of nipple contacts per bout (Mann-Whitney, N.S.); and (c) duration of suckling bouts (Mann-Whitney, N.S.).

To detect more accurately any differences that could have arisen before and after mothers came into oestrus, data were plotted in a time scale that had this event as the reference point (see 'Materials and Methods'). Because mothers which conceived did so within 1.5 months of their resumption of oestrus, a range of 1.5 months before and after the appearance of the first oestrus was considered. The mean conception date was $<1$ month after the first oestrus $(22.71 \pm 5 \cdot 71$ days, $N=7$ ). Primiparous mothers were suckling their infants more frequently than were multiparous mothers 1.5 months before they came into oestrus (Fig. 3). This difference became even more pronounced when mothers started cycling, due to the fact that suckling frequency increased for primiparous mothers at this time, while suckling frequencies remained fairly constant up to this point for multiparous mothers. In both groups, suckling frequency started declining after the return to oestrus. Although the drop in suckling frequency was marked in both groups, primiparous mothers maintained frequencies above a lower limit of around 2 bouts $/ \mathrm{h}$. In contrast, multiparous females started suckling their infants at $<1.5$ bouts/h soon after they resumed oestrus.

Infants of primiparous females made more nipple contacts/bout 2 months before their mothers came into oestrus (primiparous, $2.56 \pm 0.19, \mathrm{~N}=4$; multiparous, $1.79 \pm 0 \cdot 22, \mathrm{~N}=7$; MannWhitney, $\mathrm{U}=4, P=0.03$ ), as well as when their mothers came into oestrus (primiparous, $2 \cdot 17 \pm 0 \cdot 54$ nipple contacts/bout, $\mathrm{N}=4$, multiparous, $1.83 \pm 0 \cdot 18, \mathrm{~N}=8$ ), and thereafter (Month +1 : primiparous, $1.95 \pm 0.30, \mathrm{~N}=4$; multiparous, $1.63 \pm 0.19, \mathrm{~N}=7$ ), but the two latter differences failed to show statistical significance.

Bout duration did show differences between groups. Infants of primiparous females had suckling bouts which lasted for about $4 \mathrm{~min}$ before, during and after their mothers returned to oestrus (Month $-1,3.82 \pm 0.29$; Month 0, 3.77 \pm 1.07 , Month $+1,4.44 \pm 1.59$ ), while infants of multiparous females had consistently longer bouts (Month $-1,6 \cdot 56 \pm 1 \cdot 47$, Month 0 , 


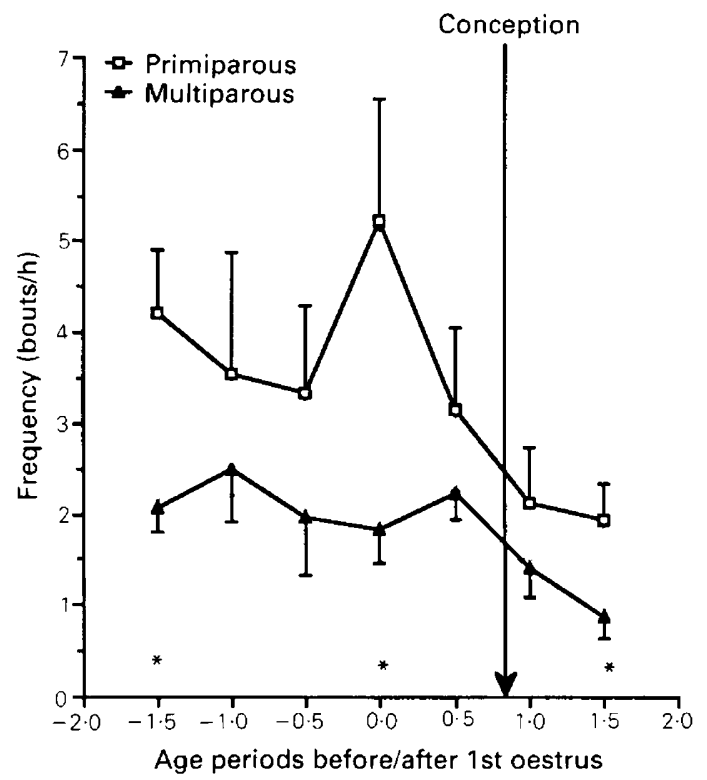

Fig. 3. Frequency of suckling bouts in relation to the appearance of first oestrus for primiparous $(\mathrm{N}=4)$ and multiparous $(\mathrm{N}=8)$ mothers. Asterisks indicate significant differences (Mann-Whitney: Month $-1 \cdot 5, \mathrm{U}=3, P=0.01$; Month 0 : $\mathrm{U}=3, P=0.01$; Month $+1 \cdot 5$, $\mathrm{U}=6, P=0.05$ ).

$6 \cdot 24 \pm 1 \cdot 05$, Month $+1,6 \cdot 89 \pm 1 \cdot 78)$. No particular changes in duration were associated with the first appearance of oestrus.

\section{Discussion}

At Madingley, most females gave birth to their first surviving infant at the age of 4 years, which also seems to be the rule among most free-living provisioned (Drickamer, 1974; Wolfe, 1986), and captive (Wilson et al., 1983, 1986) groups of this species. However, age at first reproduction tends to be delayed in primate populations in the wild, particularly when food resources are limited (reviewed in Melnick \& Pearl, 1987; Dunbar, 1988).

No differences in birth sex ratio between primiparous and multiparous mothers were found, in agreement with other reports (baboons: Altmann, 1980; macaques: Rawlins \& Kessler, 1986; Small \& Hrdy, 1986; Silk, 1988). This finding does not support the theoretical prediction that, assuming primiparous mothers are in worse physical condition than multiparous mothers (see below), sex ratio should be more female biased in the former (for an extensive discussion of sex ratio predictions see Clutton-Brock \& Iason, 1986). Due to the lack of differences in birth sex ratio, the sex of the infant can be ruled out as a potential confounding variable in this study.

Females who were delivering their first infant gave birth around the same time as multiparous non-lactating females, and significantly earlier than multiparous lactating females. Thus, lactation delayed reproduction among multiparous females, as has been found in other studies (Drickamer, 1974; Gordon, 1981; Hiraiwa, 1981; Paul \& Thommen, 1984; Scucchi, 1984; Pope et al., 1986; Wolfe, 1986; Lee, 1987; Gomendio, 1989). On the other hand, since the timing of births was similar for primiparous and multiparous non-lactating females, it follows that the former did not confront major reproductive constraints during the breeding season in which they first conceived successfully (see also Pope et al., 1986). 
A major difference in reproductive performance relied on the fact that primiparous females had longer inter-birth intervals than did multiparous females. Because macaques are seasonal breeders, failure to become pregnant during the breeding season entails a barren year. Thus, inter-birth intervals can be measured in year-units, instead of the less abrupt time differences present in nonseasonally breeding species. Depressed fertility after the first surviving infant seems to be an almost universal feature among Old World primates (see reviews by Wilson et al., 1983, 1988; Anderson, 1986; Lancaster, 1986; Nicolson, 1987), but its causation is poorly understood. To start with, several possible explanations can be ruled out. First, as already mentioned, primiparous females gave birth relatively early in the season and, therefore, the reproductive constraints that derive from late births (Drickamer, 1974; Scucchi, 1984) cannot account for the differences observed (see also Wilson et al., 1983). Second, the differences in fertility during the following breeding season can neither be attributed to age alone (i.e. adolescent status) nor pregnancy, for females of the same age which are either artificially prevented from becoming pregnant after ovulating or are separated from their first born infants just after birth, do reproduce successfully during the following breeding season (Wilson et al., 1988; see also Pope et al., 1986). The already mentioned fact that nulliparous females, who are younger than primiparous females, seem to be free from any major reproductive disadvantages when they first become pregnant, lends further support to the view that age alone cannot explain the low fertility of primiparous females.

The delay of subsequent reproduction among primiparous females therefore seems to result from a combination of low parity (or young age) and the successful rearing of the first infant. Two main hypotheses have been put forward which consider both factors simultaneously.

The first hypothesis postulates that since, among primates, primiparous females have not reached full adult stature or body weight (reviewed by Anderson, 1986; Lancaster, 1986), the costs of lactation will add to the costs of growing, resulting in an energetic burden of such magnitude that will make reproduction in the short term difficult (Wilson et al., 1978, 1988; Mori, 1979; Walker et al., 1983; Lancaster, 1984, 1986; Anderson, 1986; Nicolson, 1987). Macaque females reproduce at a particularly early stage in the course of their physical maturation, for they attain menarche when they are only $30 \%$ of the adult stature, unlike chimpanzees or humans who reach menarche when $80 \%$ and $70 \%$ respectively of full adult size has been attained (Watts \& Gavan, 1982). In macaques, menarche even precedes the beginning of the acceleration in growth rates that adolescents experience (a growth spurt, which is of minor magnitude when compared to that in humans) (Watts \& Gavan, 1982). Consequently, primiparous females tend to be smaller in size, to weigh less, and to have less body fat than do multiparous females (Mori, 1979; Walter et al., 1984; Pope et al., 1986; Wilson et al., 1988), features which are known to be reproductively disadvantageous (Frisch, 1978; Mori, 1979; Altmann, 1983; Lee, 1987; Prentice \& Whitehead, 1987; Dunbar, 1988); in addition, they grow while they are raising their infants (Wilson et al., 1988). Mothers with so few resources to spare are likely to find difficulties in coping with the energetic demands of reproduction, in particular lactation (Altmann, 1983; Prentice \& Whitehead, 1987). The problem with an argument of this kind is that it is unclear how such energetic constraints could influence fertility through changes in body condition (Prentice \& Whitehead, 1987; Berman, 1988; Lunn, 1988). A critical level of body fat has been regarded by some as essential for ovulation to occur (Frisch \& McArthur, 1974; Frisch, 1978, 1984), while this has been refuted by others (Bongaarts, 1980); hence it remains an open question whether differences in body condition could explain the delay in the appearance of oestrus that primiparous females experienced (see also Wilson et al., 1988). Once they come into oestrus, primiparous females experience repeated cycles with inadequate luteal phases, and low serum concentrations of progesterone, oestradiol, and bioactive LH (Pope et al., 1986; Wilson et al., 1988), which prevent the occurrence of a successful conception. Wilson et al. (1988) found no relation between body weight, body fat and growth rates, from the birth season to the following breeding season, and the proportion of abnormal ovulations (see also Pope et al., 1986). It could be that under optimal nutritional conditions, as was the case in their study, there is no clear relationship between various degrees of body condition and reproductive 
performance. However, their results do suggest that the decline in fertility after the first birth is not necessarily a direct result of a worsening in physical condition resulting from a combination of lactation and growth. Instead, this evidence points to the existence of other regulatory mechanisms.

The second hypothesis suggests that primiparous females may have a suckling pattern such that it prevents short-term reproduction (Walker et al., 1983; Nicolson, 1987; Wilson et al., 1988). The available evidence indicates that it is certain features of suckling patterns that influence maternal reproduction. Among these, the frequency of suckling bouts (or the duration of the interval between bouts) seems to be a key variable, while it is not clear whether the duration of the suckling bouts or the total amount of time spent suckling have any significant effect (man: Konner \& Worthman, 1980; Howie \& McNeilly, 1982; Short, 1984; Wood et al., 1985; vervets: Lee, 1987; gorillas: Stewart, 1988). Recent work on macaques has shown that lactating females which failed to reproduce experienced not only a higher frequency of suckling bouts, but also more nipple contacts per bout, than did those which did reproduce; however, conceivers and non-conceivers did not differ in the duration of the suckling bouts (Gomendio, 1989).

Thus, if primiparous mothers were suckling their infants at high rates and/or with a high number of nipple contacts per bout, this could explain their low fertility during the breeding season. The results presented in this paper show that this was certainly the case. From 4 to 12 months of age, infants of primiparous females were sucking more frequently and making more nipple contacts per bout than were infants of multiparous females. While addressing this same question, Wilson et al. (1988) obtained very different results, which indicate that, if anything, multiparous females were suckling their infants more frequently. However, the figures they present show a range of suckling frequencies from around 15 to 55 bouts/h. These values are extremely high when compared to other primate data available in the literature which tend to be surprisingly homogeneous (Clark, 1977; Nicolson, 1982; Lee, 1987; Stewart, 1988; Stewart et al., 1988; Gomendio, 1989). These differences could have arisen because of the use of a different statistical procedure to define 'suckling bout', but this is difficult to deduce from the information provided in their paper. In trying to explain the low reproductive performance of primiparous females, despite the apparent absence of differences in suckling patterns, Wilson et al. (1988) postulated that primiparous females may be more sensitive to the influence of suckling, because their neuroendocrine system is still not fully developed. In the present study, the clear differences in suckling patterns found between primiparous and multiparous mothers render such interpretation unnecessary.

Because the physiological mechanisms postulated to explain the inhibitory effect of the suckling stimulus upon ovulation are likely to act on a short time scale (Short, 1984; Pope et al., 1986; Gordon et al., 1987; McNeilly, 1988; McNeilly et al., 1988; Wilson et al., 1988), suckling patterns during the breeding season could be particularly relevant. In this study, the differences in suckling behaviour between primiparous and multiparous females became more accentuated precisely during the breeding season. While in oestrus, primiparous females suckled their infants more frequently than did multiparous females, and there was a non-significant tendency for their infants to make more nipple contacts per bout. When the changes in suckling patterns around first oestrus were examined, it was found that higher suckling frequencies among primiparous females were already present 1.5 months before this event, and that primiparous females underwent a drastic increase precisely at first oestrus, while suckling frequency remained low throughout this period for multiparous females. After the appearance of the first oestrus, suckling frequency declined for both groups of mothers, but primiparous females consistently showed higher values. Similarly, infants of primiparous mothers tended to make more nipple contacts per bout before, during, and after, first oestrus, than did infants of multiparous mothers. Hence, the high suckling frequency, as well as the presence of numerous nipple contacts per bout, could explain the occurrence of inadequate luteal phases among primiparous mothers (Pope et al., 1986; Wilson et al., 1988). Wilson et al. (1988) suggested that the fact that suckling frequences changed around ovulation could be the critical 
factor, rather than the actual frequency levels. The findings presented here show that primiparous females experienced both higher suckling frequencies and a sharp increase in this variable coinciding with the appearance of oestrus. Whether this peak is important because of the increase itself or because it entails a sudden change remains uncertain.

Suckling frequency decreased for primiparous and multiparous mothers after their return to oestrus. However, within the next 1.5 months suckling frequency in primiparous mothers was not reduced to $<2$ bouts $/ \mathrm{h}$, while multiparous mothers were suckling their infants at $<1.5$ bouts $/ \mathrm{h}$ soon after the appearance of oestrus. Average conception date actually coincided with the point at which suckling frequencies for multiparous mothers fell below 1.5 bouts $/ \mathrm{h}$. Vervet mothers, another seasonally breeding species, also seem to conceive only when suckling frequency crossed this threshold (Lee, 1987; and see also Gomendio, 1989).

The multiparous females seemed to compensate for their low suckling frequency by lengthening the duration of the suckling bouts. In this way, they seemed to be reducing those suckling variables that inhibit reproduction (i.e. frequency of bouts and number of nipple contacts), while increasing those that are not, such as bout duration. The question then arises of why primiparous females do not follow a similar strategy. Primiparous females could be forced into a reproductively inhibiting suckling pattern if they were unable to produce as much milk, or to produce it as quickly, as multiparous females (see Fowler et al., 1988). Evidence from other studies indicates that when under poor nutritional conditions mothers produce milk at slower rates, their infants respond by increasing the frequency of suckling in order to stimulate milk secretion (red deer: Loudon et al., 1983; Loudon \& Kay, 1984; man: Prentice et al., 1986; Prentice \& Whitehead, 1987; Lunn, 1988). Human babies also increase the number of sucks within a feeding episode when milk flow is slow (Drewett \& Woolridge, 1979; Bowen-Jones et al., 1982). Thus, the higher suckling frequency and numerous nipple contacts per bout shown by the infants of primiparous mothers, could be a response to slow or insufficient milk yields which, in turn, may be a consequence of the physical and developmental characteristics of primiparous mothers (i.e. low body weight and fat, continued growth). In other words, among primiparous mothers, the energetic requirements of growth could divert maternal resources away from milk production, resulting in small milk yields which, in turn would prompt more frequent nipple stimulation by their infants, ultimately resulting in delayed reproduction. This interpretation could provide a potential link between the two hypotheses discussed, since it relates energetic constraints and maternal physical condition on the one hand, to milk production and suckling patterns on the other.

Since infants born to primiparous mothers face high mortality rates (Drickamer, 1974; Mori, 1979; Altmann et al., 1988; reviews by Anderson, 1986; Lancaster, 1986), and may be bound to grow slowly, higher maternal investment could have a major impact on offspring survival (Hiraiwa, 1981). Although this is achieved at the expense of delaying future maternal reproduction, mothers themselves might gain from having time to recover from the energetic drain of lactation. It is therefore likely that over their lifetime primate mothers benefit reproductively from spacing out early births.

I thank St John's College, Cambridge, for the Research Studentship which I held during most of this study; Trinity Hall, Cambridge, for the Research Fellowship held while writing; P. P. G. Bateson, R. A. Hinde and E. B. Keverne, for providing facilities at the MRC Unit and the SubDepartment of Animal Behaviour, and for permission to study the Madingley colony, which is funded by the MRC; R. A. Hinde for constant support; M. J. A. Simpson for supervision of my work and for allowing me access to the colony data; D. Rayment for helping to identify the monkeys at the beginning, and for looking after them; S. Datta, M. Janus, D. Rayment and M. J. A. Simpson for information on the reproductive status of the females; Phyllis Lee for incisive criticism and encouragement; F. Colmenares, S. Datta, R. A. Hinde, E. B. Keverne, P. Lee, E. Roldán and M. J. A. Simpson for very useful comments on an earlier draft; and E. Roldán for help. 


\section{References}

Altmann, J. (1980) Baboon Mothers and Infants. Harvard University Press, Cambridge, MA.

Altmann, J. (1983) Costs of reproduction in baboons (Papio cynocephalus). In Behavioural Energetics: The Cost of Survival in Vertebrates, pp. 67-88. Eds W. P. Aspey \& S. I. Lustick. Ohio State University Press.

Altmann, J., Altmann, S.A. \& Hausfater, G. (1978) Primate infant's effects on mother's future reproduction. Science, NY 201, 1028-1030.

Altmann, J., Hausfater, G. \& Altmann, S.A. (1988) Determinants of reproductive success is savannah baboons, Papio cynocephalus. In Reproductive Success, pp. 403 418. Ed. T. H. Clutton-Brock. The University of Chicago Press, Chicago.

Anderson, C.M. (1986) Female age: male preference and reproductive success in primates. Int. J. Primatol. 7, 305-326.

Berman, C.M. (1988) Maternal condition and offspring sex ratio in a group of free-ranging rhesus monkeys: an eleven-year study. Am. Nat. 131, 307-328.

Bongaarts, J. (1980) Does malnutrition affect fecundity? A summary of evidence. Science, $N Y$ 208, 564-569.

Bongaarts, J. \& Potter, R.G. (1983) Fertility, Biology and Behaviour. Studies in Population. Academic Press, New York.

Bowen-Jones, A., Thompson, C. \& Drewett, R.F. (1982) Milk flow and suckling rates during breast-feeding. Dev. Med. Child Neurol. 24, 626-633.

Burton, F.D. \& Sawchuk, L.A. (1982) Birth intervals in Macaca sylvanus of Gibraltar. Primates 23, 140-144.

Campbell, K.L. \& Wood, J.W. (1988) Fertility in traditional societies. In Natural Human Fertility., Social and Biological Determinants, pp. 39-69. Eds P. Diggory, M. Potts \& S. Teper. MacMillan Press, London.

Clark, C.B. (1977) A preliminary report on weaning among chimpanzees of the Gombe National Park, Tanzania. In Primate Bio-social Development, pp. 235-260. Eds S. Chevalier-Skolnikoff \& F. E. Poirier. Garland Press, New York.

Clutton-Brock, T.H. \& Iason, G.R. (1986) Sex ratio variation in mammals. Q. Rev. Biol. 61, 339-374.

Clutton-Brock, T.H., Guinness, F.E. \& Albon, S.D. (1982a) Red Deer. Behaviour and Ecology of the Two Sexes. Edinburgh University Press, Edinburgh.

Clutton-Brock, T.H., Iason, G.R., Albon, S.D. \& Guinness, F.E. (1982b) Effects of lactation on feeding behaviour and habitat use in wild red deer hinds. $J$. Zool., Lond. 198, 227-236.

Clutton-Brock, T.H., Albon, S.D. \& Guinness, F.E. (1989) Fitness costs of gestation and lactation in wild mammals. Nature, Lond. 337, 260-262.

Czaja, J.A., Eisele, S.G. \& Goy, R.W. (1975) Cyclical changes in the sexual skin of female rhesus: relationship to mating behaviour and successful artificial insemination. Fedn. Proc. Fedn. Am. Socs. exp. Biol. 34, 1680-1684.

Dolhinow, P., McKenna, J.J. \& Vonder Haar Laws, J. (1979) Rank and reproduction among langur monkeys: aging and improvement (They're not just getting older, they're getting better). Agg. Behav. 5, 19-30.
Drewett, R.F. \& Woolridge, M. (1979) Sucking patterns of human babies on the breast. Early Human Dev. 3/4, 315-320.

Drickamer, L.C. (1974) A ten-year summary of reproductive data for free-ranging Macaca mulatta. Folia Primatol. 21, 61-80.

Dunbar, R.I.M. (1988) Primate Social Systems. Croom Helm, London.

Elias, M.F., Teas, J., Johnston, J. \& Bora, C. (1986) Nursing practices and lactational amenorrhea. $J$. biosoc. Sci. 18, 1-10.

Fowler, P.A., Knight, C.H. \& Foster, M.A. (1988) Magnetic resonance imaging (MRI) studies of udder development and milk production in primi- and multi-parous goats. J. Reprod. Fert., Abstr. Ser., 1, 60 , abstr.

Frisch, R.E. (1978) Population, food intake, and fertility. Science, NY 199, 22-30.

Frisch, R.E. (1984) Body fat, puberty and fertility. Biol. Rev. 59, 161-188.

Frisch, R.E. \& McArthur, J.W. (1974) Menstrual cycles, fatness as a determinant of minimum weight for height necessary for their maintenance or onset. Science, NY 185, 949-951.

Gomendio, M. (1988) Mother-offspring relationships and consequences for fertility in rhesus macaques. Ph.D. thesis, University of Cambridge.

Gomendio, M. (1989) Suckling behaviour and fertility in rhesus macaques. J. Zool., Lond. 217, 449-467.

Gordon, K., Renfree, M.B., Short, R.V. \& Clarke, I.J. (1987) Hypothalamo-pituitary portal blood concentrations of $\beta$-endorphin during suckling in the ewe. $J$. Reprod. Fert. 79, 397-408.

Gordon, T.P. (1981) Reproductive behaviour in the rhesus monkey: Social and endocrine variables. $\mathrm{Am}$. Zool. 21, 185-195.

Hartmann, P.E., Rattigan, S., Prosser, C.G., Saint, L. \& Arthur, P.G. (1984) Human lactation: Back to nature. Symp. zool. Soc. Lond. 51, 337-368.

Hiraiwa, M. (1981) Maternal and alloparental care in a troop of free-ranging Japanese monkeys. Primates 22, 309-329.

Howie, P.W. \& McNeilly, A.S. (1982) Effect of breast feeding patterns on human birth intervals. $J$. Reprod. Fert. 65, 545-557.

Hrdy, S.B. \& Whitten, P.L. (1987) Patterning of sexual activity. In Primate Societies, pp. 370-384. Eds B. B. Smuts, D. L. Cheney, R. M. Seyfarth, R. W. Wrangham \& T. T. Struhsaker. The University of Chicago Press, Chicago.

Konner, M. \& Worthman, C. (1980) Nursing frequency, gonadal function, and birth spacing among !Kung hunter-gatherers. Science, NY 207, 788-791.

Lancaster, J.B. (1984) Evolutionary perspectives on sex differences in the higher primates. In Gender and the Life Course, pp. 3-27. Ed. A. S. Rossi. Aldine, New York.

Lancaster, J.B. (1986) Human adolescence and reproduction: An evolutionary perspective. In School-age Pregnancy and Parenthood. Biosocial Dimensions, pp. 17-37. Eds J. B. Lancaster \& B. A. Hamburg. Aldine de Gruyter, New York. 
Lee, P.C. (1987) Nutrition, fertility and maternal investment in primates. J. Zool., Lond. 213, 409-422.

Loudon, A.S.I. \& Kay, R.N.B. (1984) Lactational constraints on a seasonally breeding mammal: The red deer. Symp. zool. Soc. Lond. 51, 233-252.

Loudon, A.S.I., McNeilly, A.S. \& Milne, J.A. (1983) Nutrition and lactational control of fertility in red deer. Nature, Lond. 302, 145-147.

Lunn, P.G. (1988) Malnutrition and fertility. In Natural Human Fertility. Social and Biological Determinants, pp. 135-152. Eds P. Diggory, M. Potts \& S. Teper. MacMillan Press, London.

Martin, P. \& Bateson, P. (1986) Measuring Behaviour. Cambridge University Press, Cambridge.

Martin, R.D. (1984) Scaling effects and adaptive strategies in mammalian lactation. Symp. zool. Soc. Lond. 51, 87-117.

McNeilly, A.S. (1988) Suckling and the control of gonadotropin secretion. In The Physiology of Reproduction, pp. 2323-2349. Eds E. Knobil \& J. Neill. Raven Press, New York.

McNeilly, A.S., Howie, P.W. \& Glasier, A. (1988) Lactation and the return of ovulation. In Natural Human Fertility. Social and Biological Determinants, pp. 102-117. Eds P. Diggory, M. Potts \& S. Teper. MacMillan Press, London.

Melnick, D.J. \& Pearl, M.C. (1987) Cercopithecines in multimale groups: genetic diversity and population structure. In Primate Societies, pp. 121-134. Eds B. B. Smuts, D. L. Cheney, R. M. Seyfarth, R. W. Wrangham \& T. T. Struhsaker. The University of Chicago Press, Chicago.

Mori, A. (1979) Analysis of population changes by measurements of body weight in the Koshima troop of Japanese monkeys. Primates 20, 371-397.

Nicolson, N.A. (1982) Weaning and the development of independence in olive baboons. Ph.D. thesis, Harvard University.

Nicolson, N.A. (1987) Infants, mothers, and other females. In Primate Societies, pp. 330-342. Eds B. B. Smuts, D. L. Cheney, R. M. Seyfarth, R. W. Wrangham \& T. T. Struhsaker. The University of Chicago Press, Chicago.

Oftedal, O.T. (1984) Milk composition, milk yield and energy output at peak lactation: A comparative review. Symp. zool. Soc. Lond. 51, 33-85.

Paul, A. \& Thommen, D. (1984) Timing of birth, female reproductive success and infant sex ratio in semifreeranging barbary macaques (Macaca sylvanus). Folia Primatol. 42, 2-16.

Pope, N.S., Gordon, T.P. \& Wilson, M.E. (1986) Age, social rank and lactational status influence ovulatory patterns in seasonally breeding rhesus monkeys. Biol. Reprod. 35, 353-359.

Prentice, A.M. \& Whitehead, R.G. (1987) The energetics of human reproduction. Symp. zool. Soc. Lond. 57, 275-304.

Prentice, A.M., Paul, A.A., Prentice, A., Black, A.E., Cole, T.J. \& Whitehead, R.G. (1986) Cross-cultural differences in lactational performance. In Human Lactation 2: Maternal and Environment Factors, pp. 13-44. Eds M. Hamosh \& A. S. Goldman. Plenum Press, New York.

Rawlins, R. \& Kessler, M. (1986) Secondary sex ratio variation in the Cayo Santiago macaque population. Am. J. Primatol. 10, 9-23.

Scucchi, S. (1984) Interbirth intervals in a captive group of Japanese macaques. Folia Primatol. 42, 203-208.

Short, R.V. (1976) The evolution of human reproduction. Proc. R. Soc. Lond. B 195, 3-24.

Short, R.V. (1984) Breast feeding. Sci. Am. 250, 35-41.

Short, R.V. (1985) Species differences in reproductive mechanisms. In Reproduction in Mammals. Vol. 4: Reproductive Fitness, pp. 24-61. Eds C. R. Austin \& R. V. Short. Cambridge University Press, Cambridge.

Silk, J.B. (1988) Maternal investment in captive bonnet macaques (Macaca radiata). Am. Nat. 132, 1-19.

Silk, J.B., Clark-Wheatley, C.B., Rodman, P.S. \& Samhels, A. (1981) Differential reproductive success and facultative adjustment of sex ratios among captive female bonnet macaques (Macaca radiata). Anim. Behav. 29, 1106-1120.

Small, M.F. \& Hrdy, S.B. (1986) Secondary sex ratios by maternal rank, parity and age in captive rhesus macaques (Macaca mulatta). Am. J. Primatol. 11, 359-365.

Sokal, R.R. \& Rohlf, F.J. (1981) Biometry, 2nd edn. Freeman \& Co., San Francisco.

Stewart, K. (1988) Suckling and lactational anoestrus in wild gorillas. J. Reprod. Fert. 83, 627-634.

Stewart, K., Harcourt, A.H. \& Watts, D.P. (1988) Determinants of fertility in wild gorillas and other primates. In Natural Human Fertility. Social and Biological Determinants, pp. 22-38. Eds P. Diggory, M. Potts \& S. Teper. MacMillan Press, London.

Strum, S.C. \& Western, D. (1982) Variations in fecundity with age and environment in olive baboons (Papio anubis). Am. J. Primatol. 3, 61-76.

Thapa, S., Short, R.V. \& Potts, M. (1988) Breast feeding, birth spacing and their effects on child survival. Nature, Lond. 335, 679-682.

Vandenbergh, J.G. \& Vessey, S.H. (1968) Seasonal breeding of free-ranging rhesus monkeys and related ecological factors. J. Reprod. Fert. 15, 71-79.

van Wagenen, G. (1972) Vital statistics from a breeding colony: reproductive and pregnancy outcome in Macaca mulatta. J. med. Primatol. 1, 3-28.

Walker, M.L., Gordon, T.P. \& Wilson, M.E. (1983) Menstrual cycle characteristics of seasonally breeding rhesus monkeys. Biol. Reprod. 29, 841-848.

Walker, M.L., Schwartz, S.M., Wilson, M.E. \& Musey, P.I. (1984) Estimation of body fat in female rhesus monkeys. Am. J. phys. Anthropol. 63, 323-329.

Watts, E.S. \& Gavan, J.A. (1982) Postnatal growth of nonhuman primates: The problem of the adolescent spurt. Hum. Biol. 54, 53-70.

Wilson, M.E. \& Gordon, T.P. (1989) Season determines timing of first ovulation in rhesus monkeys (Macaca mulatta) housed outdoors. J. Reprod. Fert. 85, 583591.

Wilson, M.E., Gordon, T.P. \& Bernstein, I.S. (1978) Timing of births and reproductive success in rhesus monkey social groups. J. med. Primatol. 7, 202-212.

Wilson, M.E., Walker, M.L. \& Gordon, T.P. (1983) Consequences of first pregnancy in rhesus monkeys. Am. J. phys. Anthropol. 61, 103-110.

Wilson, M.E., Gordon, T.P., Blank, M.S. \& Collins, D.C. (1984) Timing of sexual maturity in female rhesus 
monkeys (Macaca mulatta) housed outdoors. J. Wolfe, L. (1986) Reproductive biology of Rhesus and Reprod. Fert. 70, 625-633.

Wilson, M.E., Gordon, T.P. \& Collins, D.C. (1986) Ontogeny of luteinizing hormone secretion and first ovulation in seasonal breeding rhesus monkeys. Endocrinology 118, 293-301.

Wilson, M.E., Walker, M.L., Pope, N.S. \& Gordon, T.P. (1988) Prolonged lactational infertility in adolescent rhesus monkeys. Biol. Reprod. 38, 163-174.

Received 16 February 1989

Wood, J.W., Lai, D., Johnson, P.L., Campbell, K.L. \& Maslar, I.A. (1985) Lactation and birth spacing in Highland New Guinea. J. biosoc. Sci., Suppl. 9, 159-173. 